\title{
Gone in 60 days: our first experience with a bioconvertible IVC filter
}

\author{
Gerard Lambe ${ }^{1}\left[\right.$ ] Johnny O' Mahony ${ }^{1} \cdot$ Michael Courtney $^{1} \cdot$ Noel Donlon $^{2} \cdot$ Claire Donohoe $^{2} \cdot$ JMark Ryan $^{1}$
}

Received: 2 September 2021 / Accepted: 13 October 2021 / Published online: 2 November 2021

(c) The Author(s), under exclusive licence to Royal Academy of Medicine in Ireland 2021

\begin{abstract}
The Sentry bioconvertible IVC filter (Boston Scientific, MA, USA) contains a bioabsorbable filament which hydrolyses after 60 days, allowing the arms of the filter to spring open, retract into the vessel wall and endothelialise, leaving an unobstructed IVC lumen.

It is a novel treatment option for patients at transient risk of pulmonary emboli with a contraindication to anticoagulation. The device provides similar protection to other currently available devices against pulmonary emboli with minimal complications. It represents an effective alternative to retrievable filters, the removal of which is variously not attempted, not possible or associated with high complication rates.

We review the literature which underpins the development of the bioconvertible filter. We describe our first deployment of the filter in an 85-year-old female with gastric malignancy (who subsequently underwent a subtotal gastrectomy) with a history of anaemia and previous pulmonary emboli. The availability of a bioconvertible filter constitutes a further step forward in the management of patients with potential or active thromboembolic disease.
\end{abstract}

Keywords Anticoagulation $\cdot$ Bioconversion $\cdot$ Deep venous thrombosis $\cdot$ IVC filter $\cdot$ Pulmonary embolism $\cdot$ Retrieval

\section{Background}

The Sentry bioconvertible inferior vena cava (IVC) filter is designed to provide temporary protection against pulmonary embolic disease during transient periods of high risk [1]. The filter is made from a single piece of laser-cut nitinol formed into a cylindrical frame. The filter is designed to bioconvert after 60 days when a bioabsorbable filament made of poly-p-dioxanone hydrolyses and releases the arms of the filter. The arms retract into the vessel wall and are endothelialised, leaving an unobstructed IVC lumen (Fig. 1).

The rationale for its use and development is multifactorial.

a) The highest risk period for pulmonary emboli is the first 60 days after an index event such as hospitalisation, trauma or surgery. The majority of pulmonary emboli occur within the first 30 days $[2,3]$.

Gerard Lambe

gerard.lambe@ucdconnect.ie

1 Radiology Department, St. James's Hospital, James's Street, Dublin 8, Ireland

2 Department of Upper GI Surgery, St. James's Hospital, James's Street, Dublin 8, Ireland b) There are several complications associated with unretrieved filters including recurrent deep vein thrombosis (DVT), IVC thrombosis, organ penetration, strut fracture and migration. The risks increase with the length of time the filter is in situ [4].

c) Retrievable filters are often never retrieved for a variety of reasons, even when the initial indication for pulmonary embolic prophylaxis has passed. Retrieval rates are rarely greater than $50 \%$ and sometimes as low as $8.5 \%$ [5-7]. When retrieval is attempted, it is often technically challenging, success rates are variable and the procedure is associated with high complication rates [8].

d) Retrieval of IVC filters involves significant time and expense. Medicare data in the USA suggests that the payment provided for filter removal does not compensate for the expense of the procedure [9].

The Sentry filter has been evaluated in a multicentre prospective trial of 129 patients with either documented DVT/ PE or at temporary risk of DVT/PE. It has shown a high rate of successful bioconversion, strong protection against pulmonary emboli and a low rate of device-related complications through 2 years of follow-up [10]. 
Filtering

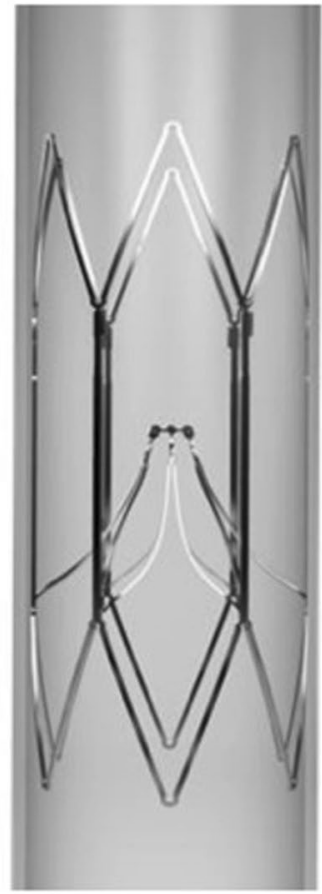

Axial view

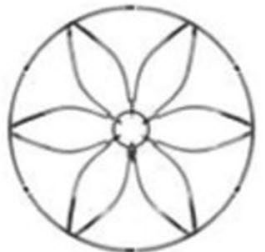

Bioconverted

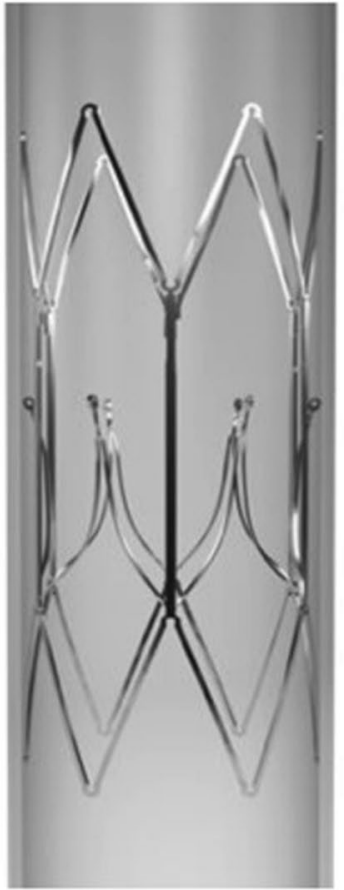

Axial view

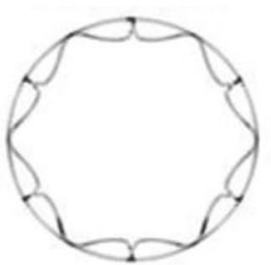

Fig. 1 Photographs from Dake et al. [25] of the Sentry IVC filter in the filtering configuration (left) and in the bioconverted configuration (right). The filter contains a bioabsorbable filament which is designed to hydrolyse after 60 days, allowing the arms of the filter to spring open, retract into the vessel wall and endothelialise, leaving an unobstructed IVC lumen

We present what we believe to be the first use of a bioconvertible IVC filter in the Republic of Ireland.

\section{Case report}

An 85-year-old female was admitted electively under the Upper GI Surgery team for a staging laparoscopy for gastric malignancy. Our institution is a tertiary referral university teaching hospital and the National Centre for Oesophageal and Gastric Cancer.

She had a recent diagnosis of COVID-19 pneumonia in another hospital which was complicated by subsegmental pulmonary emboli. She was on treatment with subcutaneous
Tinzaparin injections. She had experienced prior pulmonary emboli 8 years earlier which had been managed with Warfarin and subsequently a novel oral anticoagulant (NOAC).

Her past medical history was significant for ischaemic heart disease (with an ejection fraction of less than 30\%), type 2 diabetes mellitus, hypertension and hyperlipidaemia. Her past surgical history consisted of a hysterectomy and open appendicectomy.

She was an ex-smoker who lived with her son and daughterin-law. She was independently mobile with a frame at baseline. However, she was found to be breathless on minimal exertion on clinical evaluation.

A full blood count revealed a haemoglobin of $9.9 \mathrm{~g} / \mathrm{dL}$. Her anaemia was felt to be secondary to her gastric tumour, and a decision was made to hold her anticoagulation until a subtotal gastrectomy had been performed.

The patient's case was discussed with Interventional Radiology. It was decided, given the patient would remain at risk of further pulmonary emboli for a transient period until

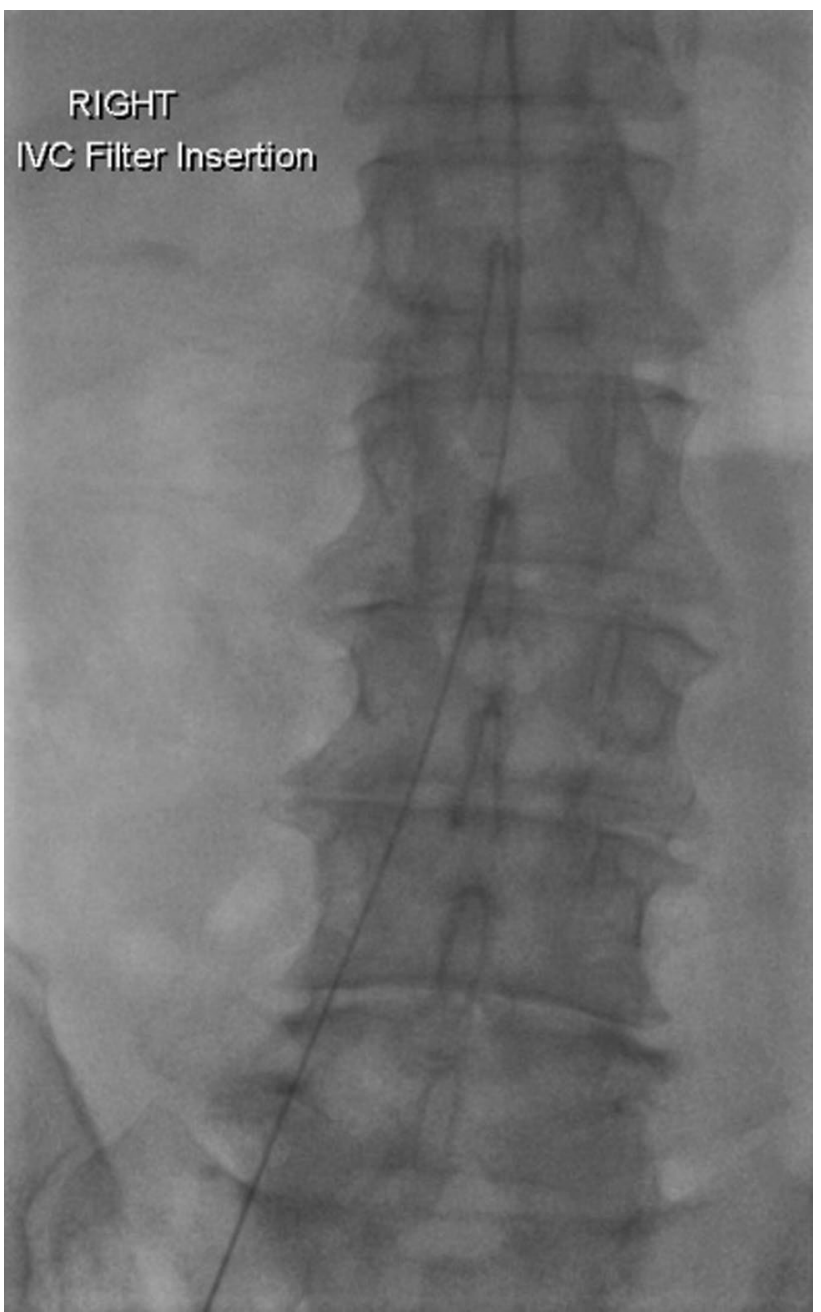

Fig. 2 A guidewire is advanced into the IVC 
her gastrectomy and for a short period after her gastrectomy, that she would be a suitable candidate for a bioconvertible IVC filter.

The procedure was discussed with the patient in Interventional Radiology, and informed consent was provided. The access site in the right groin was cleaned and draped with the patient in a supine position. The right common femoral vein was accessed using a micropuncture set consisting of a 21-gauge needle, a 0.018-inch wire and a 5 French dilator/ sheath. A guidewire was advanced into the IVC (Fig. 2).

A venogram was performed by injecting contrast through a catheter to assess for IVC patency, size and anomalies and to identify the location of the renal veins (Fig. 3). The filter

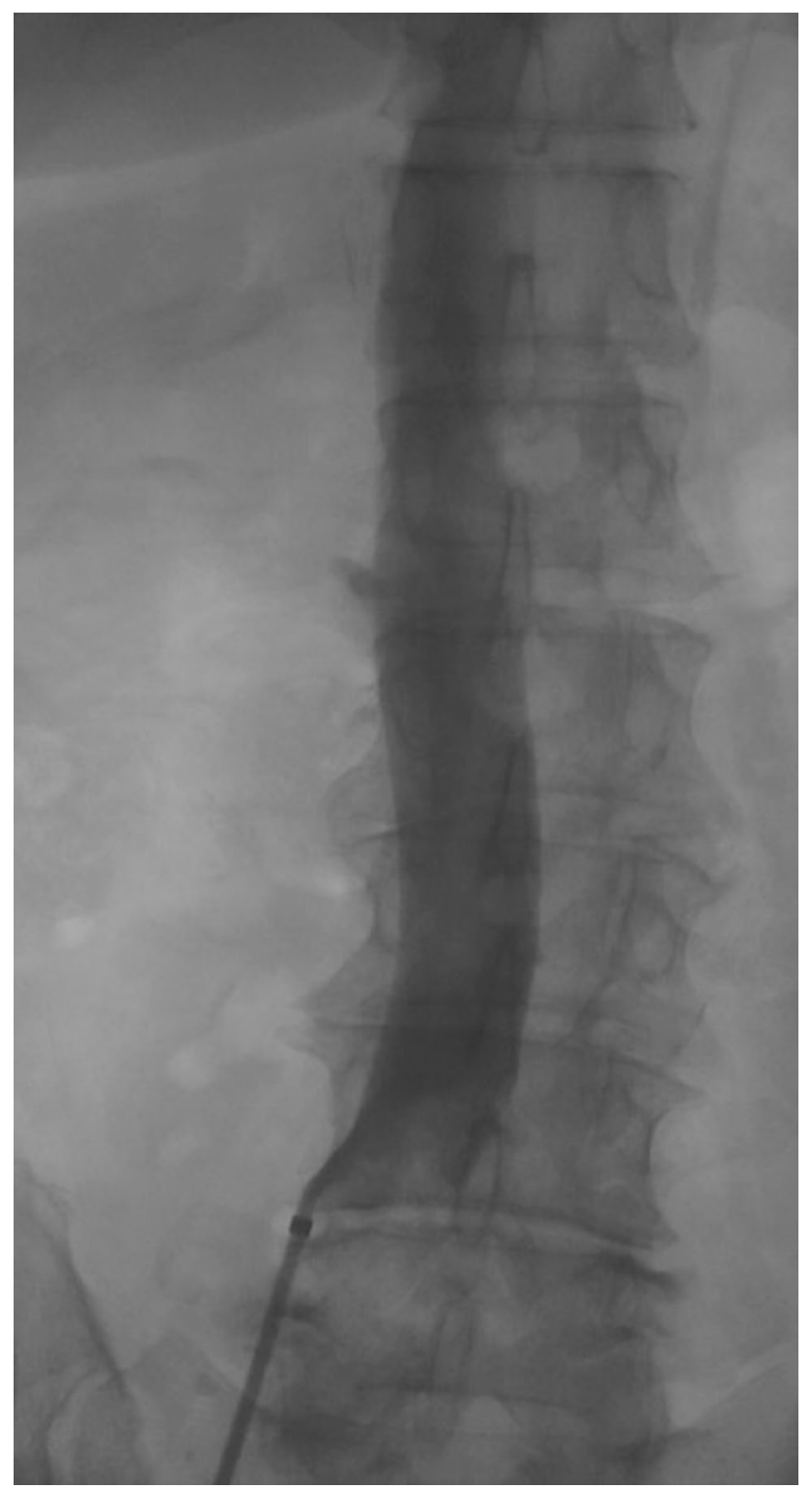

Fig. 3 A venogram is performed which confirms a single, patent IVC and the position of the renal veins was deployed through a dedicated delivery sheath (Fig. 4). A repeat venogram was performed which confirmed the satisfactory deployment of the filter (Fig. 5). The delivery sheath

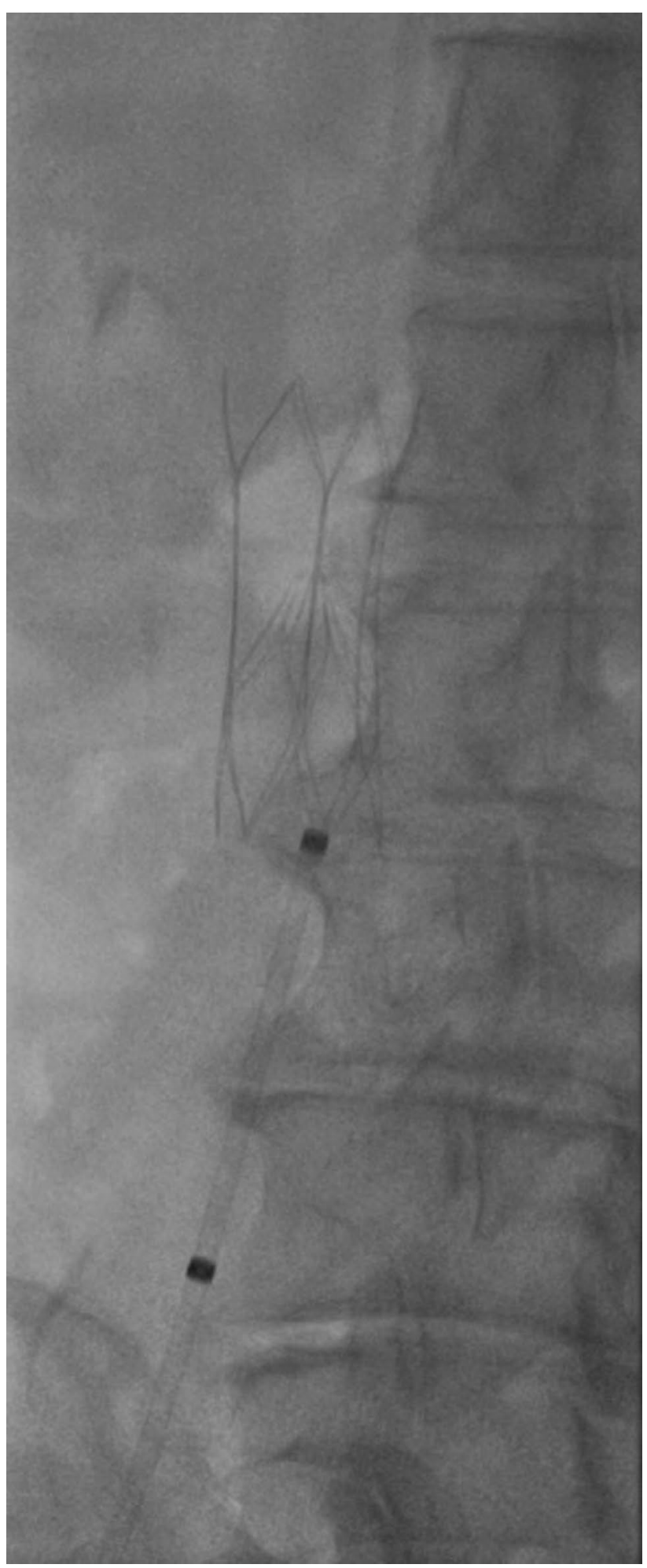

Fig. 4 The filer is deployed in the IVC 


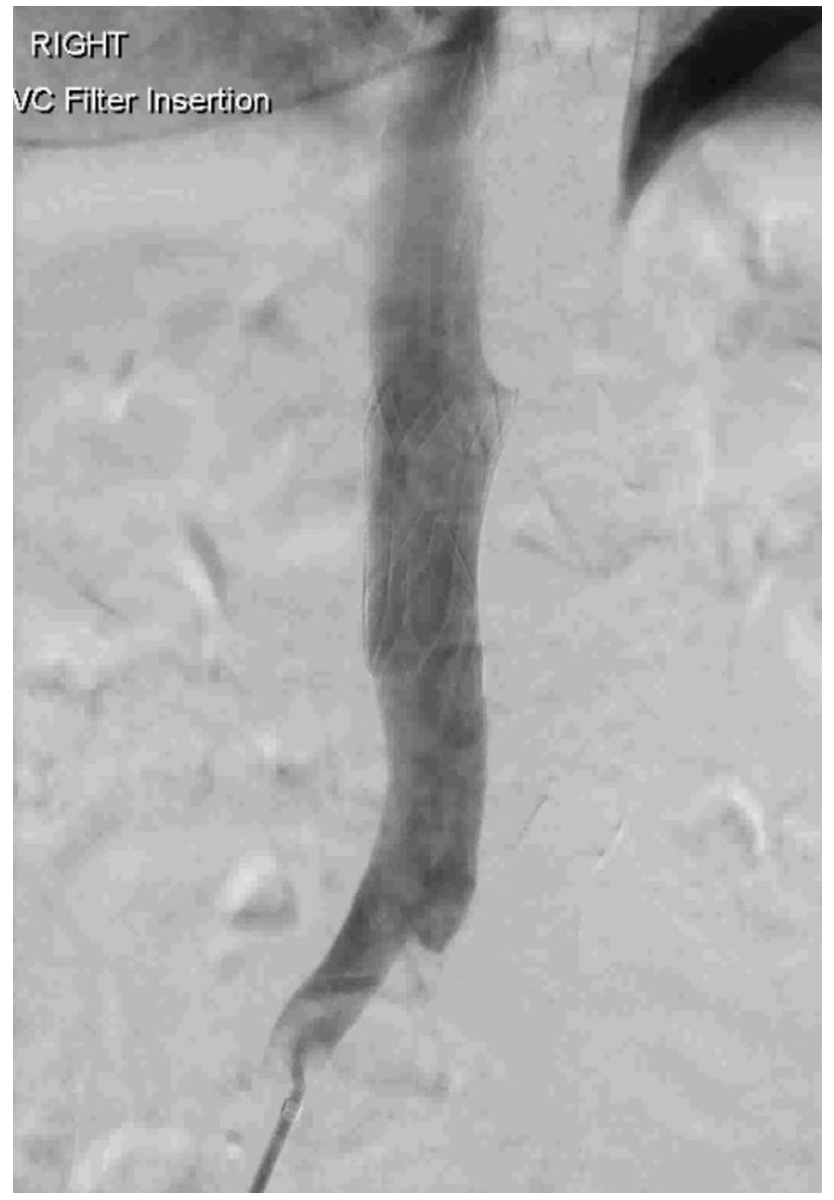

Fig. 5 A repeat venogram is performed which confirms satisfactory deployment of the filter

was removed, and haemostasis was achieved with manual compression.

The patient was successfully discharged home the following day. She returned for a subtotal gastrectomy as planned 3 weeks later.

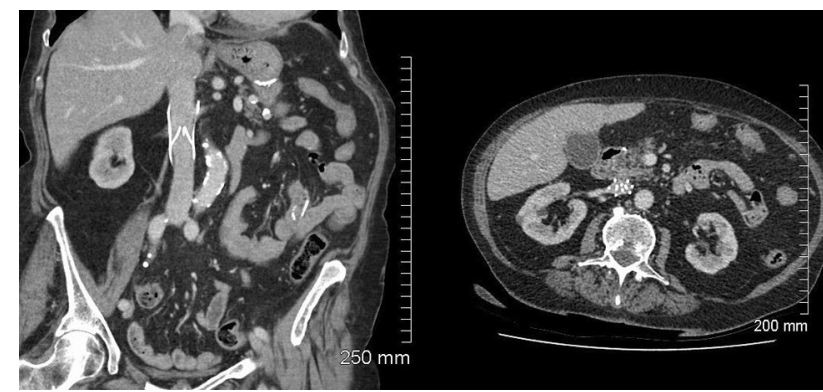

Fig. 6 Coronal (left) and axial (right) CT images in the early postoperative period demonstrate the filter in its expected filtering configuration with the arms of the filter held together by a bioabsorbable filament

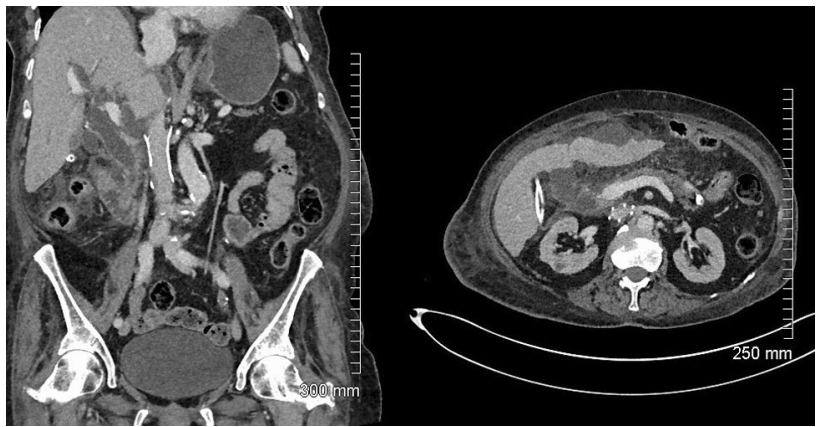

Fig. 7 Coronal (left) and axial (right) CT images between 5 and 6 months later reveal interval bioconversion of the filter. The filter arms have been released and have retracted to the vessel wall leaving an unobstructed lumen

Follow-up CT images demonstrated the filter in its filtering configuration (Fig. 6) and subsequently in its bioconverted configuration (Fig. 7).

\section{Discussion}

Venous thromboembolism comprises DVT and PE and represents a major cause of global morbidity and mortality, affecting millions of people every year [11]. It is the third most common cause of death from cardiovascular disease after myocardial infarction and stroke $[12,13]$.

Anticoagulation is the standard of care for patients with known DVT/PE or at risk of DVT/PE [14]. When anticoagulation is contra-indicated or not effective, an IVC filter may be considered in line with careful patient selection criteria devised by many societies and expert panels $[15,16]$. Evidence from systematic reviews has shown that IVC filters are effective at providing mechanical protection against pulmonary emboli $[5,17,18]$.

The concept of IVC interruption to prevent the migration of emboli was first mentioned by Armand Trosseau in 1865 [19]. Surgically inserted IVC filters were pioneered in the 1960s but found little favour until a percutaneous insertion technique was introduced by Greenfield in 1973 [20]. This was followed by the emergence of retrievable IVC filters in the 1990s [21]. For the first time, devices could now be removed when the period of high risk for the pulmonary embolic disease had passed.

The retrievable filters were granted approval by the US Food and Drug Administration (FDA) for both temporary and permanent indications, but it was expected that the majority of these filters would be removed. However, this has not been the experience either internationally or in 
Ireland. Retrieval rates are as rarely greater than $50 \%$ and sometimes as low as 8.5\% [5-7]. An Irish study of fiftyseven patients who underwent IVC filter insertion over a 22-month period found that filter retrieval was attempted in $48.9 \%$ with a technical removal success rate of $86.9 \%$ [22].

Complications associated with long-term filters include DVT, IVC thrombosis, organ penetration, strut fracture and migration. The risks appear to increase with the length of time the filter is in situ [4].

The Sentry device is the world's first bioconvertible IVC filter. It offers protection against pulmonary emboli during a transient risk period without the need for a second procedure to remove it and without the complications of long-term or permanent filters.

The filter was evaluated in a multicentre prospective trial of 129 patients with either documented DVT/PE or at temporary risk of DVT/PE [10]. The rate of new symptomatic PE was $0 \%(n=126)$ through one year and $2.4 \%$ $(n=85)$ through the second year. Results through the first year compare favourably with PE rates in recent trials of retrievable filters $[23,24]$. Both non-fatal PEs in the second year occurred long after the transient risk period and were judged by the Central Events Committee to be unrelated to the device or procedure.

Symptomatic IVC thrombosis occurred in two patients (1.6\%) within the first month. Both cases were successfully treated without recurrence. There were no episodes of filter tilting, migration, embolisation, fracture or IVC perforation through 2 years. There were no filter-related deaths. The filter successfully bioconverted in $95.7 \%$ of patients at 6 months, $96.4 \%$ at 12 months and $96.5 \%$ at 24 months.

For patients at transient risk of pulmonary emboli who have a contraindication to anticoagulation, a bioconvertible IVC filter appears to provide strong protection against PEs with minimal complications. It offers a new and effective alternative to retrievable IVC filters which are often not removed and where removal is associated with high complication rates. The availability of a bioconvertible filter in the Republic of Ireland represents another important management tool in the treatment of patients with potential or active thromboembolic disease.

\section{Declarations}

Ethics approval No identifiable patient data were used. All images have been anonymised. This article does not contain any studies with human participants or animals performed by any of the authors.

Conflict of interest The authors declare no competing interests.

\section{References}

1. Dake MD, Ansel GM, Johnson MS et al (2019) The clinical rationale for the sentry bioconvertible inferior vena cava filter for the prevention of pulmonary embolism. Int J Vasc Med 2019:5795148. https://doi.org/10.1155/2019/5795148

2. Hope WW, Demeter BL, Newcomb WL et al (2007) Postoperative pulmonary embolism: timing, diagnosis, treatment, and outcomes. Am J Surg 194:814-818; discussion 818-819. https://doi.org/10. 1016/j.amjsurg.2007.08.014

3. Coleman JJ, Zarzaur BL, Katona CW et al (2015) Factors associated with pulmonary embolism within 72 hours of admission after trauma: a multicenter study. J Am Coll Surg 220:731-736. https:// doi.org/10.1016/j.jamcollsurg.2014.12.032

4. Zhou D, Spain J, Moon E et al (2012) Retrospective review of 120 celect inferior vena cava filter retrievals: experience at a single institution. J Vasc Interv Radiol 23:1557-1563. https://doi.org/ 10.1016/j.jvir.2012.08.016

5. Angel LF, Tapson V, Galgon RE et al (2011) Systematic review of the use of retrievable inferior vena cava filters. J Vasc Interv Radiol 22:1522-1530.e3. https://doi.org/10.1016/j.jvir.2011.08.024

6. Jia Z, Fuller TA, McKinney JM et al (2018) Utility of retrievable inferior vena cava filters: a systematic literature review and analysis of the reasons for nonretrieval of filters with temporary indications. Cardiovasc Intervent Radiol 41:675-682. https://doi. org/10.1007/s00270-018-1880-9

7. Sarosiek S, Crowther M, Sloan JM (2013) Indications, complications, and management of inferior vena cava filters: the experience in 952 patients at an academic hospital with a level I trauma center. JAMA Intern Med 173:513-517. https://doi.org/10.1001/ jamainternmed.2013.343

8. KB Quencer TA Smith A Deipolyi et al 2020 Procedural complications of inferior vena cava filter retrieval, an illustrated review. CVIR Endovasc 3. https://doi.org/10.1186/s42155-020-00113-6

9. Centers for Medicare \& Medicaid Services (2016) Medicare Outpatient Hospital Standard Analytical File, US Department of Health and Human Services, Baltimore, MD, USA

10. Dake MD, Murphy TP, Krämer AH et al (2020) Final two-year outcomes for the sentry bioconvertible inferior vena cava filter in patients requiring temporary protection from pulmonary embolism. J Vasc Interv Radiol 31:221-230.e3. https://doi.org/10. 1016/j.jvir.2019.08.036

11. ISTH Steering Committee for World Thrombosis Day (2014) Thrombosis: a major contributor to the global disease burden. J Thromb Haemost 12:1580-1590. https://doi.org/10.1111/jth.12698

12. Anderson FA, Wheeler HB, Goldberg RJ et al (1991) A populationbased perspective of the hospital incidence and case-fatality rates of deep vein thrombosis and pulmonary embolism. The Worcester DVT Study. Arch Intern Med 151:933-938

13. Naess IA, Christiansen SC, Romundstad P et al (2007) Incidence and mortality of venous thrombosis: a population-based study. J Thromb Haemost 5:692-699. https://doi.org/10.1111/j.15387836.2007.02450.x

14. Tapson VF (2008) Acute pulmonary embolism. N Engl J Med 358:1037-1052. https://doi.org/10.1056/NEJMra072753

15. ACR-SIR-SPR (2016) practice parameter for the performance of infe rior vena cava (IVC) filter placement for the prevention of pulmonary embolism. https://www.acr.org/-/media/ACR/Files/ Practice-Parameters/ivc-fiterplacement.pdf?la=en

16. Guyatt GH, Akl EA, Crowther M et al (2012) Executive summary: antithrombotic therapy and prevention of thrombosis, 9th ed: American College of Chest Physicians Evidence-Based Clinical Practice Guidelines. Chest 141:7S-47S. https://doi.org/10.1378/ chest.1412S3 
17. Bikdeli B, Chatterjee S, Desai NR et al (2017) Inferior vena cava filters to prevent pulmonary embolism: systematic review and meta-analysis. J Am Coll Cardiol 70:1587-1597. https://doi.org/ 10.1016/j.jacc.2017.07.775

18. Haut ER, Garcia LJ, Shihab HM et al (2014) The effectiveness of prophylactic inferior vena cava filters in trauma patients: a systematic review and meta-analysis. JAMA Surg 149:194-202. https:// doi.org/10.1001/jamasurg.2013.3970

19. Trousseau A (1865) Phlegmasia alba dolens. Clinique Medicale de l'Hotel-Dieu de Paris 3(94):654-712

20. Becker DM, Philbrick JT, Selby JB (1992) Inferior vena cava filters. Indications, safety, effectiveness. Arch Intern Med 152:1985-1994

21. Stein PD, Kayali F, Olson RE (2004) Twenty-one-year trends in the use of inferior vena cava filters. Arch Intern Med 164:15411545. https://doi.org/10.1001/archinte.164.14.1541

22. Kok HK, Salati U, O'Brien C et al (2015) Inferior vena cava filter insertion and retrieval patterns in a tertiary referral centre in Ireland. Ir J Med Sci 184:345-348. https://doi.org/10.1007/ s11845-014-1116-1
23. Stavropoulos SW, Sing RF, Elmasri F et al (2014) The DENALI Trial: an interim analysis of a prospective, multicenter study of the Denali retrievable inferior vena cava filter. J Vasc Interv Radiol 25(1497-1505):1505.e1. https://doi.org/10.1016/j.jvir.2014.07. 001

24. Smouse HB, Mendes R, Bosiers M et al (2013) The RETRIEVE trial: safety and effectiveness of the retrievable crux vena cava filter. J Vasc Interv Radiol 24:609-621. https://doi.org/10.1016/j. jvir.2013.01.489

25. Dake MD, Murphy TP, Krämer AH et al (2018) One-year analysis of the prospective multicenter SENTRY clinical trial: safety and effectiveness of the novate sentry bioconvertible inferior vena cava filter. J Vasc Interv Radiol 29:1350-1361.e4. https://doi.org/10. 1016/j.jvir.2018.05.009

Publisher's Note Springer Nature remains neutral with regard to jurisdictional claims in published maps and institutional affiliations. 